\title{
A facile route to hydrophilic ionic liquids $\uparrow$
}

Cite this: RSC Adv., 2014, 4, 30267

Received 23rd May 2014

Accepted 30th June 2014

DOI: $10.1039 / c 4 r a 04884 a$

www.rsc.org/advances

\author{
Alexandra Alvarez Fernandez, Marcel J. A. van Dongen, Daniel Blanco-Ania \\ and Paul H. J. Kouwer*
}

Ionic liquids, organic room-temperature molten salts have percolated into many fields of science. A major problem for many applications, however, is caused by the commonly fluorinated anion, that on contact with water decomposes to release HF. Ionic liquids with hydrophilic anions do not have these problems. In addition, because of their tuneable hydrophilicity, they interface better with biotechnology, providing a route to truly 'tuneable water.' Currently available synthetic routes, however, contain strong disadvantages which may have caused the underexposure of this class of ionic liquids. In this manuscript, we provide a novel facile route to ionic liquid crystals with different hydrophilic anions, yielding pure materials as a result of our very mild reaction conditions. Our generic approach may be used to prepare conventional ionic liquids, but also provides access to functionalised ionic liquids.

\section{Introduction}

Ionic liquids (ILs) are organic materials with melting points below $100{ }^{\circ} \mathrm{C}$, but more commonly below room temperature. As the properties of both the cation and anion can be tuned independently, they are highly customisable solvents. ${ }^{1}$ Their ionic nature yields a negligible vapour pressure ${ }^{2}$ which initially captured the interest of industry to replace volatile organic compounds (VOCs) with ILs as 'green' solvents. ${ }^{3}$ Nowadays, however, many additional fields of science utilised the advantages that ILs offer, ${ }^{4}$ In fact, they are now commercially applied in separation technology, as cellulose solvents, paint additives and in batteries and solar cells that use their electro-chemical properties. ${ }^{5}$ Besides their use as merely advanced solvents, ILs can readily be functionalised to actively participate in their application, for instance as a catalyst or to tether a catalyst to the IL. The potential of this class of functional ILs, commonly referred to as task-specific ionic liquids ${ }^{6}$ (TSILs) is rapidly developing judging by their expanding application range in, f.i. (bio)catalysis, ${ }^{1 a, 4 a, 7,8}$ electrochemical cells, ${ }^{9}$ actuators ${ }^{10}$ and gas absorption. ${ }^{11}$

The development in ionic liquids has primarily focused on hydrophobic (often $\mathrm{BF}_{4}{ }^{-}, \mathrm{PF}_{6}{ }^{-}$and $\mathrm{Tf}_{2} \mathrm{~N}^{-}$) and halide anions. ${ }^{1}$ In aqueous environments many of these fluorine containing anions degrade, resulting in HF formation, a process also contributing to the toxicity effects observed for these materials., ${ }^{5,12}$ ILs with hydrophilic anions such as carboxylates or amino acid derivatives ${ }^{13}$ avoid such problems and interface more naturally with biotechnology. In addition, hydrophilic ILs

Radboud University Nijmegen, Institute for Molecules and Materials, Heyendaalseweg 135, 6525 AJ Nijmegen, The Netherlands. E-mail: p.kouwer@science.ru.nl

$\uparrow$ Electronic supplementary information (ESI) available: Synthetic procedures and analyses. See DOI: $10.1039 / \mathrm{c} 4 \mathrm{ra04884a}$ have recently successfully been developed for aqueous biphasic liquid-liquid separation techniques..$^{14}$ They are, however, much more challenging to obtain in acceptably pure grades. Currently, two major synthetic approaches are applied in the synthesis of such ILs; both have major disadvantages. ${ }^{15}$ One approach relies on anion metathesis from hydroxides, ${ }^{13,16}$ which are not stable and result in impure final products. ${ }^{11 c, 17}$ The other approach uses carbonate-based processes. ${ }^{18}$ Although this route yields stable precursors, their preparation requires thermally demanding conditions and exclude common substitution patterns and many functional groups. For instance, the alkyl carbonate-based CBIL $\odot$ process ${ }^{18 c}$ allows no substituents at the reactive $\mathrm{C}(2)$ position in of the commonly used imidazolium ILs, despite the universally accepted instability of the attached proton. ${ }^{11,19}$ Alternative routes invariably require stringent purification procedures, which are difficult for ILs in general but even more so for hydrophilic ones, as the ionic byproducts are partially soluble in the main product. For instance, commonly found trace impurities are halides that have shown to produce inactive catalyst species or irreproducible results due to varying levels between different batches of the same material. ${ }^{20}$

In order to reliably access this class of hydrophilic ionic liquids alternative synthetic approaches are needed which (a) are quantitative chemical transformations, avoiding cumbersome purification processes; (b) do not rely on halide exchange, avoiding trace ionic impurities; or (c) avoid ionic impurities altogether.

In this work, we present a novel route to hydrophilic ILs, yielding clean products solely using very mild conditions. We designed versatile generic ionic precursors that can be reacted to yield conventional ionic liquids, but can also be used to introduce functional groups establishing a mild route to hydrophilic TSILs. The precursors 1-3 (Scheme 1) are readily 


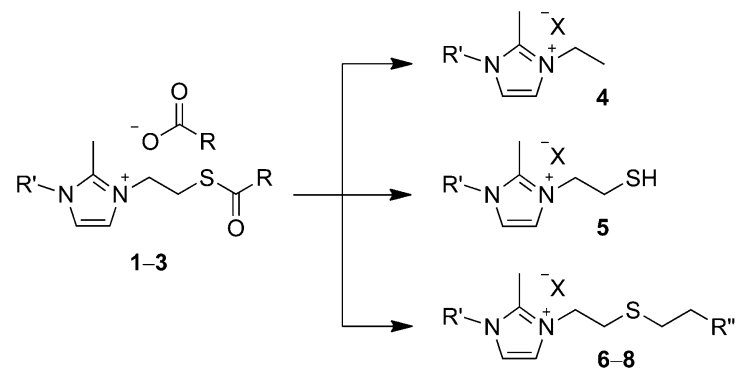

Scheme 1 Generic IL/TSIL precursor approach. Precursors $1-3$ can be modified to either yield standard ILs 4 with a range of counter ions or to give TSILs $5-8$, also with a range of counter ions.

available from commercial starting materials in a mild one-step reaction; they are stable over time, pure and halogen-free. The reduction of the precursor provides conventional 1-ethyl-2,3-dimethyl-imidazolium-based ILs (4), where the carboxylic anion can be replaced quantitatively with a range of other hydrophilic anions, allowing fine-tuning of the physicochemical properties of the IL. In addition, we exploit the sulfanyl group to generate TSILs (5-8) using straightforward Michael addition chemistry. Importantly, our modification strategies leave the anion intact and avoid the introduction of ionic impurities such as halides.

\section{Results and discussion}

\section{Precursors}

The key one-step reaction towards precursors 1-3 is based on the ring opening reaction of thiirane by an $\mathrm{N}$-substituted 2-methylimidazole using a carboxylic acid anhydride as solvent (Table 1). This approach allows for the presence of a methyl group at the imidazole's 2-position instead of the labile proton $^{11 c, 21}$ that is present in many commercial ILs. The reaction generates the imidazolium cation in the presence of a carboxylate counter ion, free from any ionic impurities. The reaction conditions required optimization to obtain sufficiently high yields, but even at optimized conditions (entries 6 and 7) the reaction is still relatively slow.

Experiments showed that decreased thiirane concentrations (entries 1 and 2) slightly lower the yield. Reactions at excess sulfide concentrations were not considered as thiirane oligomerization is anticipated to compete. The anhydrides required distillation prior to use, since acid impurities (entry 3 ) inhibited the reaction, presumably the result of protonation of the imidazole rendering it unreactive. Heating the reaction mixture to $35{ }^{\circ} \mathrm{C}$ (entries 4 and 5) increases the reaction rate, however, the formation of side products limited the total yield obtained (vide infra). ${ }^{22}$

Carrying out the reaction in the presence of other acid anhydrides, such as propionic, valeric and pivalic anhydrides introduces the opportunity to tune the properties of the precursor and subsequently derived ionic liquids in one single step by simply replacing the carboxylate anion. The use of more sterically hindered anhydrides substantially reduces the reaction rate (entries 7-10). On the other hand, reaction with more activated anhydrides such as trifluoroacetic anhydride fails entirely (entry 11).

If one simply considers the reaction as two consecutive steps - first the ring opening of the thiirane by the attack of the

Table 1 Reaction conditions ${ }^{a}$ and yields ${ }^{b}$ for the precursor synthesis

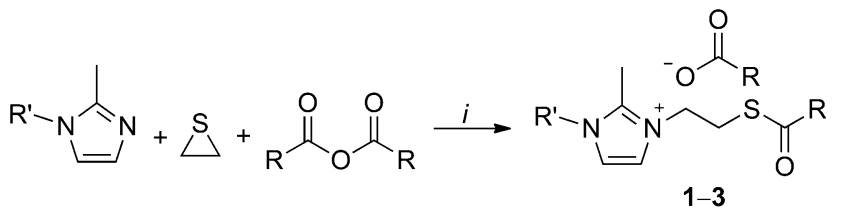

Molar reactant ratios

\begin{tabular}{|c|c|c|c|c|c|c|c|c|}
\hline Entry & $\mathrm{R}$ & $\mathrm{R}^{\prime}$ & $N$-Alkyl-2-methylimidazole & Thiirane & Anhydride & Product & Time (days) & Yield (\%) \\
\hline 1 & $\mathrm{CH}_{3}$ & $\mathrm{CH}_{3}$ & 1 & 1 & 5 & 1a & 1 & 10 \\
\hline 2 & $\mathrm{CH}_{3}$ & $\mathrm{CH}_{3}$ & 1 & 1 & 5 & 1a & 7 & 58 \\
\hline $3^{c}$ & $\mathrm{CH}_{3}$ & $\mathrm{CH}_{3}$ & 1 & 1 & 5 & 1a & 7 & 0 \\
\hline $4^{d}$ & $\mathrm{CH}_{3}$ & $\mathrm{CH}_{3}$ & 1 & 1 & 5 & 1a & 1 & 35 \\
\hline $5^{d}$ & $\mathrm{CH}_{3}$ & $\mathrm{CH}_{3}$ & 1 & 1 & 5 & 1a & 7 & 38 \\
\hline 6 & $\mathrm{CH}_{3}$ & $\mathrm{CH}_{3}$ & 1 & 2 & 5 & 1a & 7 & 64 \\
\hline 7 & $\mathrm{CH}_{3}$ & $\mathrm{CH}_{3}$ & 1 & 2 & 5 & 1a & 14 & 81 \\
\hline 8 & $\mathrm{CH}_{2} \mathrm{CH}_{3}$ & $\mathrm{CH}_{3}$ & 1 & 2 & 5 & $1 b$ & 14 & 60 \\
\hline 9 & $\left(\mathrm{CH}_{2}\right)_{3} \mathrm{CH}_{3}$ & $\mathrm{CH}_{3}$ & 1 & 2 & 5 & $1 \mathrm{c}$ & 14 & 56 \\
\hline 10 & $\mathrm{C}\left(\mathrm{CH}_{3}\right)_{3}$ & $\mathrm{CH}_{3}$ & 1 & 2 & 5 & $1 d$ & 14 & $30^{e}$ \\
\hline 11 & $\mathrm{CF}_{3}$ & $\mathrm{CH}_{3}$ & 1 & 2 & 5 & $1 e$ & 14 & n.d. ${ }^{f}$ \\
\hline 12 & $\mathrm{CH}_{3}$ & $\left(\mathrm{CH}_{2}\right)_{5} \mathrm{CH}_{3}$ & 1 & 2 & 5 & $2 a$ & 14 & 77 \\
\hline 13 & $\mathrm{CH}_{3}$ & $\left(\mathrm{CH}_{2}\right)_{11} \mathrm{CH}_{3}$ & 1 & 2 & 5 & $3 \mathbf{a}$ & 14 & 48 \\
\hline
\end{tabular}

${ }^{a}$ Reaction conditions: neat (no solvent) typically $1 \mathrm{~mL}$ imidazole scale, room temperature, argon atmosphere. ${ }^{b}$ Yields determined from ${ }^{1} \mathrm{H}$ NMR spectra of the reaction mixture. ${ }^{c}$ Addition of $0.5 \mathrm{~mL}$ acetic acid. ${ }^{d}$ Reaction at $T=35{ }^{\circ} \mathrm{C} .{ }^{e}$ Product precipitated from the reaction mixture as a white solid. ${ }^{f}$ n.d. $=$ not determined. 
imidazole followed by the fast quenching of the thiolate anion by the anhydride solvent-one would not expect a strong dependency of the anhydride on the rate. In line with our experimental observations, we anticipate that a more complex reaction sequence is involved (Scheme 2).

We propose that ionic liquids 1-3 are formed by a ring opening reaction of thiiranium III by 1-alkyl-2-methylimidazole I (Scheme 2, step iii). This intermediate is formed by the reaction of thiirane with the anhydride solvent that is catalysed by the imidazole starting material I (steps i and ii) with II as intermediate. $^{23}$ The thiiranium salt III reacts slower with external nucleophiles as the $\mathrm{R}$ group becomes larger, in line with the reduced reaction rates for bulkier anhydrides. In a competing side reaction IV (step iv) is generated. The rate of the intramolecular reaction iv will be independent of the alkyl substitution of $\mathbf{I}$. As the rate of product formation decreases with the increasing alkyl tail size, the yields of precursor 1-3 decrease as the competing side reaction becomes, relatively, progressively faster (Table 1, entries 7-10).

The reaction is not limited to small imidazolium-based ILs. Intermediate and long aliphatic tails may be introduced at the 1-position of the starting imidazole, opening the route towards (functional) ionic liquid crystals. ${ }^{24}$ As a demonstration, two $\mathrm{N}$ alkylated imidazoles were reacted with thiirane in acetic anhydride (entries 12 and 13). With the longer alkyl tails, we found a reduced solubility in acetic anhydride and to counter an additional contribution to the already low reaction rates, the reaction mixture may be heated slightly (with the risk of the above mentioned side reactions), or, alternatively, $n$-pentane may be added to the reaction mixture.

The precursors 1-3 were dried under high vacuum for $24 \mathrm{~h}$, prior to further analysis. According to ${ }^{1} \mathrm{H}$ and ${ }^{13} \mathrm{C} \mathrm{NMR}$ all compounds (besides 2a and 3a) present a dimeric counter ion that mostly resembles a hydrogen dicarboxylate as only one set of peaks are found in the spectra of the anion. ${ }^{25}$ A dimeric or even oligomeric carboxylate anion has been reported for more ionic liquids, ${ }^{\mathbf{1 1 c , 2 6}}$ but the relation between the structure of the cation and anion to the number of molecules present in the anion remains unknown.

Thioesters 1-3 are versatile and stable precursors towards common and functional ILs. In our lab, they are commonly

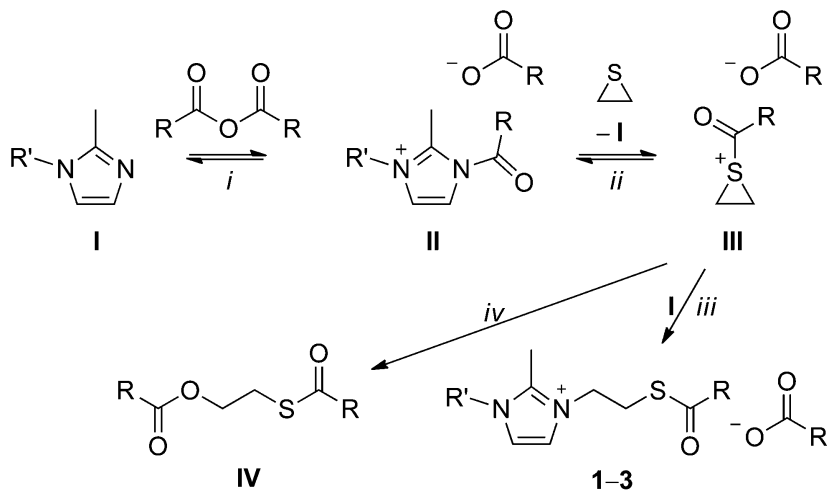

Scheme 2 Proposed reaction sequence for the formation of IL precursors 1-3. stored for months in solution of the carboxylic anhydride they were made from without noticeable degradation, but also after purification they can be stored for extended periods of time. Most of our products are isolated as yellowish liquids (at room temperature). Only 1d with the pivalate counter ion is a solid at room temperature, which allows for easy purification by recrystallization, yielding a white solid.

In the next sections of the manuscript we will address modification procedures of the precursors 1-3, converting the thioester group by hydrogenolysis, ammonolysis (or hydrolysis) or by an addition reaction to yield either common or functional ILs. In parallel, we will discuss and compare two different materials: acetate 1a, with the smallest counter ion, its reactions are relatively fast; and pivalate $\mathbf{1 d}$, it offers the opportunity to generate very pure (TS)ILs with zero optical absorption in the visible part of the spectrum, which remains a true challenge in the IL field. ${ }^{27}$

\section{Hydrogenolysis}

Conventional ILs $\mathbf{4 a}$ and $\mathbf{4 d}$ of the type EMIm (but with the additional stabilizing methyl group at the 2-position) were formed by reductive cleavage of the corresponding thioesters $\mathbf{1 a}$ and 1d, respectively (Scheme 3). Although a wide range of different catalytic methods to reduce the $\mathrm{C}-\mathrm{S}$ bond of a thioester have been reported, ${ }^{28}$ only a few would succeed preserving the (hydrophilic) counter ion. This requires that reagents and byproducts should in principle be non-ionic in nature and separable from the reaction mixture. Based on these demands, we selected Raney ${ }^{\circledR}$ nickel $/ \mathrm{H}_{2}$ as the method of choice to hydrogenolyze the thio-ester. ${ }^{29}$ Raney ${ }^{\circledR}$ nickel was thoroughly washed with solvents and activated with acetic acid ${ }^{30}$ (or pivalic acid for reactions with 1d) prior to use. In our first attempts 1a was subjected to hydrogenolysis under various conditions (different solvents: methanol, ethanol or water). The reaction was quantitative and rapid (2-4 h). Analysis of the crude mixture by NMR, however, showed the absence of any acetate signals in the product, indicating complete replacement of the counter ion, even when the reaction was stopped after a few minutes or when the reaction was run in the presence of excess acetic acid. ${ }^{31}$ Efforts to reintroduce the acetate counter ion proved unsuccessful.

When pivalate 1d was subjected to the same hydrogenolysis conditions, the reaction was much slower (room temperature,

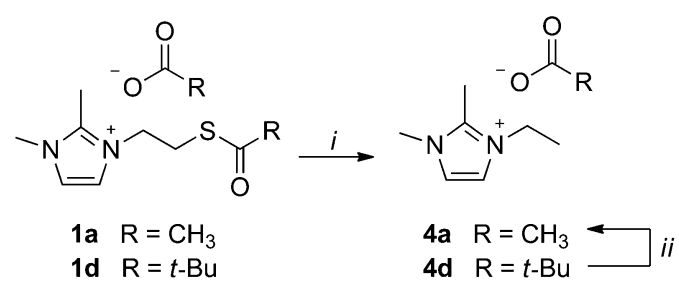

Scheme 3 Thioester hydrogenolysis towards conventional ILs with carboxylate counter ions. Key: (i) $\mathrm{H}_{2}, \mathrm{RCO}_{2} \mathrm{H}$-activated Raney ${ }^{\circledR} \mathrm{Ni}$, $\mathrm{EtOH}$, room temperature, 1-16 h, 92\%; (ii) $\mathrm{AcOH}$ (excess) and precipitation, $98 \%$. 
overnight, quantitative conversion). Remarkably, product analysis after purification of the reaction mixture showed the pivalate counter ion present in the product, in this case in a $1: 1$ ratio to the cation. That is, the additional equivalent of pivalic acid present in 1d was not observed in $\mathbf{4 d}$. Subsequent washing and precipitation steps allowed for a quantitative ion exchange of $\mathbf{4 d}$ into $4 \mathbf{a}$; the latter also missed the additional equivalent acetic acid in the product.

\section{Ammonolysis of the precursors}

To be able to employ the built-in thiol functional group, compounds 1a-1d required deacylation. Ammonium and imidazolium decorated thiols find application in metal nanoparticle stabilization where the sulfide strongly binds to the metal (e.g., $\mathrm{Au}, \mathrm{Pt}, \mathrm{Pd}$ ) surface. ${ }^{32}$ The ionic group in these coatings facilitates stabilization through coulombic repulsion.

Such ligand can be readily obtained through an ammonolysis reaction in aqueous ammonia (Scheme 4$)$. Thioester $1 \mathbf{a}(\mathrm{R}=$ $\mathrm{CH}_{3}$ ) was fully converted to $\mathbf{5 a}$ in $30 \mathrm{~min}$. The acetamide byproduct was removed by azeotropic distillation with $o$-xylene, resulting in a pure product without further purification. The resulting thiol, however, was not stable over time under basic conditions as a result of oxidative dimerization of the thiol to the corresponding disulfide. The rate of dimerization of $\mathbf{5 a}$, compared to simple aliphatic thiols, was remarkably high and heating accelerated dimer formation. Precursors with bigger counter ions (1b-1d) were also efficiently ammonolyzed, however, the products are much more difficult to purify from the amide byproducts. Prolonged heating resulted invariably in dimerization of the product. In cases when applications require IL dimers, compounds $\mathbf{5 a - 5 d}$ can be mildly oxidized in DMSO solution. Reductions from the dimer to the free thiol can be carried out using phosphines in the reaction mixture. ${ }^{33}$

As an alternative route, hydrolysis was carried out in aqueous methanol with triethylamine as a base (Scheme 4). The reaction was clean, but much slower than the ammonia route. The low reaction rate led to significant dimerization during the reaction and the pure thiol could only be obtained after an additional reduction step.

\section{Functionalization of the precursors}

The strongly nucleophilic thiol is an excellent starting group for the introduction of functional groups to generate TSILs. ${ }^{34} \mathrm{We}$ demonstrated this concept by performing thia-Michael

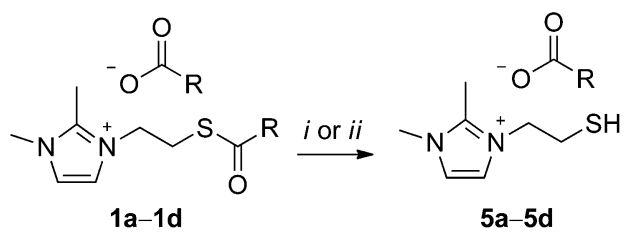

Scheme 4 Precursor hydrolysis. Key: (i) aq. $\mathrm{NH}_{3}$, room temperature, 30 min, quantitative, conversion > 98\%; (ii) $\mathrm{NEt}_{3}$, aq. $\mathrm{MeOH}$, room temperature, $>5$ days (no yield determined). additions with three different acceptors, although many other acceptors and even other reactions are conceivable.

The thia-Michael addition reaction was successfully carried out with thiols $\mathbf{5}$, but we found in our lab that the in situ hydrolysis and Michael reaction gave TSILs in higher yield and purity (Scheme 5). To the hydrolysis reaction mixture was added an excess of the desired Michael acceptor, which captured the thiol from solution. The high reaction rate of the second step, compared to the first causes the concentration of thiol to be very low during the course of the reaction, efficiently preventing dimerization. The reaction was performed with three different Michael acceptors: acrylonitrile to yield $\mathbf{6 a}$, ethyl acrylate to yield 7a and penten-3-one to give 8a. Typical reaction times were of the order of days, as a result of the slow hydrolysis reaction at room temperature. Bulky esters, such as 1b-1d, react even slower and require heating for practical application. In our hands, 1d showed full conversion to $\mathbf{6 d}$ (Scheme 5, conditions (ii)) without the formation of detectable amounts of side products, and thus, yielding a very pure, non-colored TSIL.

\section{Ion exchange}

The anions of ILs have a large impact on their ultimate properties. ${ }^{11 a, 35}$ Using our anhydride method, we can introduce different carboxylate anions in the first step of the reaction. The downside of this approach is that, in particular for the larger, more sterically demanding carboxylates, subsequent reactions become sluggish. The acetate counter ion, however, allows easy exchange with many acids of lower $\mathrm{p} K_{\mathrm{a}}$ or acids with higher
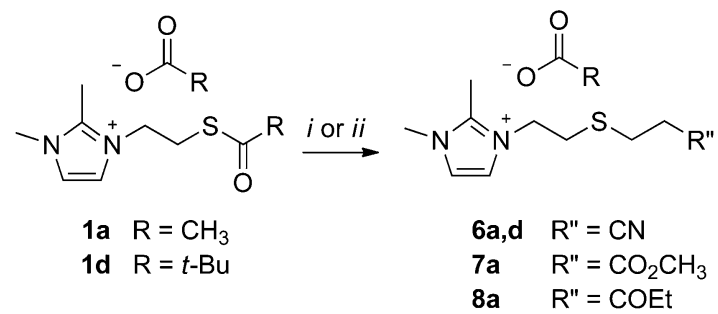

Scheme 5 Thiol functionalization. Key: (i) $\mathrm{NEt}_{3}$, aq. $\mathrm{MeOH}$, Michael acceptor (acrylonitrile, ethyl acrylate or penten-3-one), room temperature, 5 days, 89-92\%; (ii) $\mathrm{NEt}_{3}, \mathrm{EtOH}-\mathrm{H}_{2} \mathrm{O}$ (4 : 1), acrylonitrile, reflux, 5 days, $87 \%$.

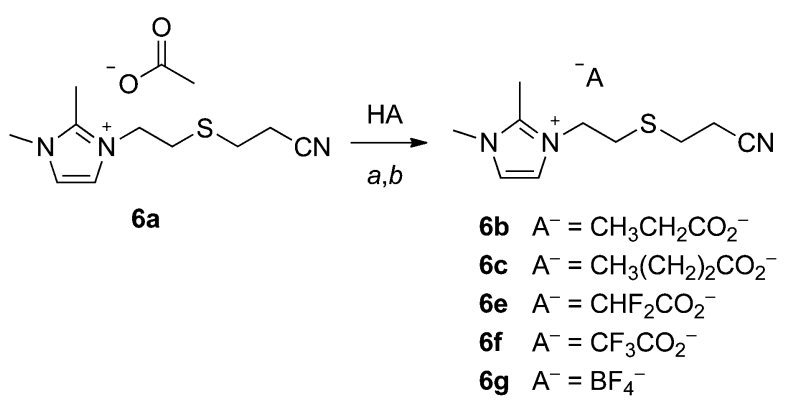

Scheme 6 Ion-exchange reactions. Key: (a) HA (excess), $\mathrm{MeOH}$, room temperature, $5 \mathrm{~min}$; (b) evaporation of the volatiles (and optionally a precipitation procedure). 
Table 2 Results of ion exchange and counter ion complexes of 6

\begin{tabular}{llllll}
\hline Entry & Anion & Product $^{a}$ & Yield \% & Phase at 25 ${ }^{\circ} \mathrm{C}$ & \# molecules/anion \\
\hline 1 & $\mathrm{CH}_{3} \mathrm{CO}_{2}{ }^{-}$ & $\mathbf{6 a}$ & 90 & Liquid & 2 \\
2 & $\mathrm{CH}_{3} \mathrm{CH}_{2} \mathrm{CO}_{2}^{-}$ & $\mathbf{6 b}$ & 92 & Liquid & 1 \\
3 & $\mathrm{CH}_{3}\left(\mathrm{CH}_{2}\right)_{2} \mathrm{CO}_{2}^{-}$ & $\mathbf{6 c}$ & 86 & Solid & 1 \\
4 & $\left(\mathrm{CH}_{3}\right)_{3} \mathrm{CCO}_{2}^{-}$ & $\mathbf{6 d}$ & 92 & Liquid & 1 \\
5 & $\mathrm{CHF}_{2} \mathrm{CO}_{2}{ }^{-}$ & $\mathbf{6 e}$ & 97 & Liquid & 2 \\
6 & $\mathrm{CF}_{3} \mathrm{CO}_{2}^{-}$ & $\mathbf{6 f}$ & 87 & Liquid & 2 \\
7 & $\mathrm{BF}_{4}^{-}$ & $\mathbf{6 g}$ & 92 & Solid & n.d.
\end{tabular}

${ }^{a}$ Yields for ion exchange reactions are quantitative. ${ }^{b}$ Number of carboxylate/carboxylic acid molecules in the anion complex, based on ${ }^{1} \mathrm{H}$ and ${ }^{19} \mathrm{~F}$ NMR spectroscopy. ${ }^{c}$ Obtained from the direct conversion of $\mathbf{1 d}$ with acrylonitrile to $\mathbf{6 d}($ Scheme 5$) .{ }^{d}$ n.d. $=$ not determined.

boiling temperatures. Scheme 6 shows the exchange reactions of 6a to ILs with different carboxylic anions, the same ions as prepared for 1 . Also less basic (e.g. $\left.\mathrm{CF}_{3} \mathrm{CO}_{2}{ }^{-}, \mathbf{6 f}\right)$ are now easily accessible, as are the more conventional inorganic anions (e.g., $\left.\mathrm{BF}_{4}{ }^{-}, \mathbf{6 g}\right)$. One should note that Michael adducts containing acid-sensitive groups such as carboxylic esters will be sensitive to hydrolysis in the ion exchange reactions of low $\mathrm{p} K_{\mathrm{a}}$ acids.

As a standard procedure, acetate $\mathbf{6 a}$ was dissolved in dry methanol under an inert atmosphere. The acid of the desired counter ion was added dropwise to the stirred mixture, after which the volatiles in the mixture were simply evaporated. Subsequent analysis showed that the products $6 \mathbf{b}-\mathbf{6 g}$ were free of acetic acid. Potentially included excess acid was removed by precipitation of the product in ethyl acetate or diethyl ether and subsequent overnight drying with heating in vacuo. This straightforward exchange procedure presents an excellent alternative for the introduction of the desired anion from the anhydride (Table 1).

Carboxylates $\mathbf{6 c}$ and $\mathbf{6 g}$ were obtained as low-melting-point solids, whereas the other five end products were room temperature ILs (Table 2). Spectroscopic analysis pointed out that the ILs with the smaller carboxylic anions form dimeric anions ${ }^{11 c}$ whereas the larger anions were monomeric in nature. Our initial thoughts are that this effect will be dependent on size and polarity of the molecule as well as on packing arguments in the solid state. At this stage, however, we have an insufficiently large data set to indicate which of the parameters dominates. Our results do show that both the anion and the cation play a role and we stress that in applications of ILs or TSILs, sensitive to Brønsted-Lowry acids, the additional equivalent of acid should be considered.

\section{Conclusions}

In this manuscript, we introduce a new precursor to generate conventional and functional ILs. The advantages of our approach over currently existing approaches are: (i) the precursor reaction conditions are very mild, allowing for the introduction of different functional groups in the IL; (ii) a wide range of hydrophobic and hydrophilic carboxylate anions can be readily introduced in the IL; (iii) very pure, non-colored materials are accessible; and (iv) a wide range of functional groups can be introduced through the (protected) thiol group in the precursor. To get to these results, we developed chemistry that is fully compatible with ionic liquids (in for instance reaction conditions and purification procedures) with a particular eye on the retention of the hydrophilic counter ions. In future work, we will use this approach to systematically change the properties of the counter ion in order to map out their effects on the physical properties of the ILs.

\section{Experimental section}

As examples, the optimized conditions for the syntheses of 1a, 4d, 5a, 6a and $\mathbf{6 b}$ are given below. Detailed experimental procedures, analysis and spectral assignments are provided in the ESI. $\dagger$

\section{3-[2-(Acetylsulfanyl)ethyl]-1,2-dimethyl-1H-imidazolium acetate (1a)}

A mixture of 1,2-dimethylimidazole $(10 \mathrm{mmol})$, thiirane (20 mmol) and acetic anhydride $(50 \mathrm{mmol})$ was stirred without solvent at $25{ }^{\circ} \mathrm{C}$ for 14 days. The crude product was dissolved in dichloromethane $(10 \mathrm{~mL})$ and precipitated in diethyl ether $(200 \mathrm{~mL})$. The mixture was centrifuged and the ether layer was removed. The product was reprecipitated twice and subsequently dried in vacuo to give a brown liquid in $81 \%$ yield. ${ }^{1} \mathrm{H}$ $\mathrm{NMR}, 400 \mathrm{MHz}, \mathrm{CDCl}_{3}, \delta$ ppm: $7.47(\mathrm{~d}, 1 \mathrm{H}, J=2.1 \mathrm{~Hz}), 7.34(\mathrm{~d}$, $1 \mathrm{H}, J=2.0 \mathrm{~Hz}), 4.40(\mathrm{t}, 2 \mathrm{H}, J=6.9 \mathrm{~Hz}), 3.88(\mathrm{~s}, 3 \mathrm{H}), 3.28(\mathrm{t}, 2 \mathrm{H}$, $J=6.9 \mathrm{~Hz}), 2.78$ (s, 3H), 2.33 (s, 3H), 1.97 (s, 6H). ${ }^{13} \mathrm{C} \mathrm{NMR}, 125$ $\mathrm{MHz}, \mathrm{CDCl}_{3} \delta$ ppm: 195.29, 175.78, 144.58, 122.45, 121.84, 47.90, 35.46, 30.50, 28.23, 22.39 (s), 9.90. HRMS for $\mathrm{C}_{9} \mathrm{H}_{15} \mathrm{~N}_{2} \mathrm{OS}$ : calcd: 199.09051 . Found: 199.09157.

\section{1,2-Dimethyl-3-ethyl-1 $\mathrm{H}$-imidazolium pivalate (4d)}

Prior to hydrogenolysis, the Raney ${ }^{\circledR}$ nickel catalyst was treated: 1 gram of the catalyst was stirred for $15 \mathrm{~min}$ in a $0.1 \mathrm{M}$ aqueous pivalic acid solution $(100 \mathrm{~mL})$. The catalyst was filtered off and washed with MilliQ water $(5 \times 100 \mathrm{~mL})$ and ethanol $(5 \times$ $200 \mathrm{~mL})$. Compound $1 \mathbf{d}(0.5 \mathrm{mmol})$ was dissolved in ethanol $(50 \mathrm{~mL})$ and a large excess of treated Raney® nickel catalyst was added. The reaction mixture was stirred overnight under hydrogen pressure (50 bar). The catalyst was filtered off, washed with ethanol $(3 \times 20 \mathrm{~mL})$ and the filtrate was evaporated to 
dryness. The crude product was dissolved in methanol $(10 \mathrm{~mL})$ and precipitated in diethyl ether $(200 \mathrm{~mL})$. The product was reprecipitated twice and subsequently dried in vacuo, yielding a white solid in $92 \%$ yield. ${ }^{1} \mathrm{H} \mathrm{NMR}, 400 \mathrm{MHz}, \mathrm{CD}_{3} \mathrm{OD}, \delta \mathrm{ppm}$ : $7.51(\mathrm{~d}, 1 \mathrm{H}, J=2.1 \mathrm{~Hz}), 7.45(\mathrm{~d}, 1 \mathrm{H}, J=2.1 \mathrm{~Hz}), 4.17$ (q, 2H, $=$ $7.3 \mathrm{~Hz}), 3.79$ (s, 3H), 2.59 (s, 3H), 1.43 (t, 3H, $J=7.3 \mathrm{~Hz}), 1.15$ (s, 9H). ${ }^{13} \mathrm{C}$ NMR, $125 \mathrm{MHz}, \mathrm{CD}_{3} \mathrm{OD}: 186.13,144.16,122.17,120.03$, 43.06, 39.43, 33.78, 27.47, 13.67, 7.87. HRMS for $\mathrm{C}_{7} \mathrm{H}_{13} \mathrm{~N}_{2}$ : calcd: 125.10787. Found: 125.10985.

\section{1,2-Dimethyl-3-(2-sulfanylethyl)-1 $H$-imidazolium acetate (5a)}

Compound $1 \mathrm{a}(10 \mathrm{mmol})$ was dissolved in ammonia $(100 \mathrm{~mL}, 2$ $M$ in water) and stirred in an inert atmosphere. After $30 \mathrm{~min}$. the solution was evaporated to dryness. Additional water was removed by the addition and evaporation of toluene $(3 \times$ $200 \mathrm{~mL}$ ) and the product was subsequently dried in vacuo to yield a brown liquid in $>98 \%$ conversion. ${ }^{1} \mathrm{H} \mathrm{NMR}, 400 \mathrm{MHz}$, $\mathrm{CDCl}_{3}, \delta$ ppm: 7.49 (d, $\left.1 \mathrm{H}, J=2.1 \mathrm{~Hz}\right), 7.46(\mathrm{~d}, 1 \mathrm{H}, J=2.1 \mathrm{~Hz})$, $4.45(\mathrm{t}, 2 \mathrm{H}, J=6.5 \mathrm{~Hz}), 3.78(\mathrm{~s}, 3 \mathrm{H}), 3.15(\mathrm{t}, 2 \mathrm{H}, J=6.5 \mathrm{~Hz}), 2.60$ (s, 3H), 1.85 (s, 6H). ${ }^{13} \mathrm{C}$ NMR, $100 \mathrm{MHz}, \mathrm{CD}_{3} \mathrm{OD}: 176.70,144.93$, 122.39, 121.09, 49.98, 35.71, 34.04, 21.35, 8.38. HRMS for $\mathrm{C}_{7} \mathrm{H}_{13} \mathrm{~N}_{2} \mathrm{~S}$ : calcd: 157.07994. Found: 157.08164 .

\section{3-\{2-[(2-Cyanoethyl)sulfanyl $]$ ethyl $\}-1,2-$ dimethyl-1 $H$ - imidazolium acetate $(6 a)$}

A mixture of 1a $(1 \mathrm{mmol})$, triethylamine $(10 \mathrm{mmol})$ and acrylonitrile $(5 \mathrm{mmol})$ in ethanol $(100 \mathrm{~mL})$ was stirred at room temperature for 5 days and afterwards dried in vacuo. Analogous to the workup of 1a, the crude mixture was dissolved in dichloromethane $(10 \mathrm{~mL})$ and precipitated in diethyl ether $(200$ $\mathrm{mL}$ ) three times. The final product was dried in vacuo at $50{ }^{\circ} \mathrm{C}$ to yield a brown solid in $90 \%$ yield. ${ }^{1} \mathrm{H} \mathrm{NMR}, 400 \mathrm{MHz}, \mathrm{CDCl}_{3}, \delta$ ppm: $7.92(\mathrm{~d}, 1 \mathrm{H}, J=2.1 \mathrm{~Hz}), 7.44(\mathrm{~d}, 1 \mathrm{H}, J=2.1 \mathrm{~Hz}), 4.49(\mathrm{t}, 2 \mathrm{H}$, $J=6.5 \mathrm{~Hz}), 3.86(\mathrm{~s}, 3 \mathrm{H}), 3.17(\mathrm{t}, 2 \mathrm{H}, J=6.5 \mathrm{~Hz}), 2.84(\mathrm{t}, 2 \mathrm{H}, J=$ $6.4 \mathrm{~Hz}), 2.72(\mathrm{t}, 2 \mathrm{H}, J=6.5 \mathrm{~Hz}), 2.63(\mathrm{~s}, 3 \mathrm{H}), 1.94(\mathrm{~s}, 6 \mathrm{H}) .{ }^{13} \mathrm{C}$ $\mathrm{NMR}, 75 \mathrm{MHz}, \mathrm{CDCl}_{3}, \delta \mathrm{ppm}: 176.15,144.42,122.70,122.29$, 118.77, 48.10, 35.45, 31.62, 27.79, 23.60, 18.99, 10.23. HRMS for $\mathrm{C}_{10} \mathrm{H}_{16} \mathrm{~N}_{3} \mathrm{~S}$ : calcd: 210.10649 . Found: 210.10688 .

\section{3-\{2-[(2-Cyanoethyl)sulfanyl]ethyl $\}-1,2-$ dimethyl-1H- imidazolium propionate (6b)}

To a stirred solution of $5 \mathbf{a}(10 \mathrm{mmol})$ in methanol $(10 \mathrm{~mL})$, an excess of propionic acid was added. After addition, the reaction mixture was dried in vacuo to remove the acetic acid and the crude product was precipitated three times from dichloromethane $(10 \mathrm{~mL})$ into diethyl ether $(200 \mathrm{~mL})$ and extensively dried in vacuo at $35{ }^{\circ} \mathrm{C}$ to yield a brown liquid in $92 \%$ yield. ${ }^{1} \mathrm{H}$ $\mathrm{NMR}, 400 \mathrm{MHz}, \mathrm{CDCl}_{3}, \delta$ ppm: 8.25 (d, 1H, $J=2.1 \mathrm{~Hz}$ ), 7.29 (d, $1 \mathrm{H}, J=2.0 \mathrm{~Hz}), 4.57(\mathrm{t}, 2 \mathrm{H}, J=6.3 \mathrm{~Hz}), 3.86(\mathrm{~s}, 3 \mathrm{H}), 3.10(\mathrm{t}, 2 \mathrm{H}$, $J=6.3 \mathrm{~Hz}), 2.88-2.80(\mathrm{~m}, 2 \mathrm{H}), 2.80-2.71(\mathrm{~m}, 2 \mathrm{H}), 2.68(\mathrm{~s}, 3 \mathrm{H})$, $2.24(\mathrm{q}, 2 \mathrm{H}, J=7.6 \mathrm{~Hz}), 1.09$ (t, 3H, $J=7.6 \mathrm{~Hz}) .{ }^{13} \mathrm{C}-\mathrm{NMR}, 75$ $\mathrm{MHz}, \mathrm{CDCl}_{3}, \delta$ ppm: 178.83, 145.38, 122.96, 121.40, 120.76, 47.73 , 35.21, 31.65, 31.25, 27.37, 18.85, 10.72, 9.67. HRMS for $\mathrm{C}_{10} \mathrm{H}_{16} \mathrm{~N}_{3} \mathrm{~S}$ : calcd: 210.10649 . Found: 210.10685 .

\section{Acknowledgements}

We acknowledge the EU for financial support under through the ITN project Hierarchy (PITN-CT-2007-215851).

\section{Notes and references}

1 Recent reviews on ionic liquids: (a) J. P. Hallett and T. Welton, Chem. Rev., 2011, 111, 3508-3576; (b) H. Niedermeyer, J. P. Hallett, I. J. Villar-Garcia, P. A. Hunt and T. Welton, Chem. Soc. Rev., 2012, 41, 7780-7802; (c) T. Torimoto, T. Tsuda, K.-I. Okazaki and S. Kuwabata, Adv. Mater., 2010, 22, 1196-1221.

2 Despite the negligible vapor pressure, destillation of some ILs has been reported: M. J. Earle, J. M. S. S. Esperanca, M. A. Gilea, J. N. Canongia Lopes, L. P. N. Rebelo, J. W. Magee, K. R. Seddon and J. A. Widegren, Nature, 2006, 439, 831-834.

3 (a) P. Wasserscheid and W. Keim, Angew. Chem., Int. Ed., 2000, 39, 3772-3789; (b) T. Welton, Chem. Rev., 1999, 99, 2071-2084.

4 (a) P. Domínguez de María, Angew. Chem., Int. Ed., 2008, 47, 6960-6968; (b) M. Smiglak, A. Metlen and R. D. Rogers, Acc. Chem. Res., 2007, 40, 1182-1192.

5 M. Petkovic, K. R. Seddon, L. P. N. Rebelo and C. Silva Pereira, Chem. Soc. Rev., 2011, 40, 1383-1403.

6 (a) S. K. Tang, G. A. Baker and H. Zhao, Chem. Soc. Rev., 2012, 41, 4030-4066; (b) R. Giernoth, Angew. Chem., Int. Ed., 2010, 49, 2834-2839.

7 J. H. Davis, Jr, Chem. Lett., 2004, 33, 1072-1077.

8 (a) F. van Rantwijk and R. A. Sheldon, Chem. Rev., 2007, 107, 2757-2785; (b) Z. Yang and W. Pan, Enzyme Microb. Technol., 2005, 37, 19-28.

9 (a) D. R. MacFarlane, M. Forsyth, P. C. Howlett, J. M. Pringle, J. Sun, G. Annat, W. Neil and E. I. Izgorodina, Acc. Chem. Res., 2007, 40, 1165-1173; (b) H. Ohno, Electrochemical Aspects of Ionic Liquids, Wiley, Hoboken, N.J., 2011.

10 W. Lu, A. G. Fadeev, B. Qi, E. Smela, B. R. Mattes, J. Ding, G. M. Spinks, J. Mazurkiewicz, D. Zhou, G. G. Wallace, D. R. MacFarlane, S. A. Forsyth and M. Forsyth, Science, 2002, 297, 983-987.

11 (a) J. L. Anthony, J. L. Anderson, E. J. Maginn and J. F. Brennecke, J. Phys. Chem. B, 2005, 109, 6366-6374; (b) P. J. Dyson, G. Laurenczy, C. Andre Ohlin, J. Vallance and T. Welton, Chem. Commun., 2003, 2418-2419; (c) G. Gurau, H. Rodríguez, S. P. Kelley, P. Janiczek, R. S. Kalb and R. D. Rogers, Angew. Chem., Int. Ed., 2011, 50, 1202412026; (d) D. J. Tempel, P. B. Henderson, J. R. Brzozowski, R. M. Pearlstein and H. Cheng, J. Am. Chem. Soc., 2007, 130, 400-401.

12 C.-W. Cho, T. Phuong Thuy Pham, Y.-C. Jeon and Y.-S. Yun, Green Chem., 2008, 10, 67-72.

13 K. Fukumoto, M. Yoshizawa and H. Ohno, J. Am. Chem. Soc., 2005, 127, 2398-2399.

14 S. Shahriari, L. C. Tome, J. M. M. Araujo, L. P. N. Rebelo, J. A. P. Coutinho, I. M. Marrucho and M. G. Freire, $R S C$ Adv., 2013, 3, 1835-1843. 
15 Straightforward anion metathesis, known for hydrophobic ILs fails in many cases since the (halogen containing) salt byproduct is often (partially) soluble in the hydrophilic product, hampering efficient purification.

16 S. Himmler, A. König and P. Wasserscheid, Green Chem., 2007, 9, 935.

17 H. Rodriguez, G. Gurau, J. D. Holbrey and R. D. Rogers, Chem. Commun., 2011, 47, 3222-3224.

18 (a) N. J. Bridges, C. C. Hines, M. Smiglak and R. D. Rogers, Chem.-Eur. J., 2007, 13, 5207-5212; (b) J. D. Holbrey, W. M. Reichert, I. Tkatchenko, E. Bouajila, O. Walter, I. Tommasi and R. D. Rogers, Chem. Commun., 2003, 2829; (c) R. L. Kalb, US Pat., 8,075,803, 2011.

19 In our laboratory, we exclusively use 2-methyl imidazolium ILs, to avoid side reactions involving the acidic proton at the 2-position.

20 (a) V. Gallo, P. Mastrorilli, C. F. Nobile, G. Romanazzi and G. P. Suranna, Dalton Trans., 2002, 4339-4342; (b) L. L. Lazarus, C. T. Riche, N. Malmstadt and R. L. Brutchey, Langmuir, 2012, 28, 15987-15993; (c) K. R. Seddon, A. Stark and M.-J. Torres, Pure Appl. Chem., 2000, 72, 2275-2287; (d) A. Stark, P. Behrend, O. Braun, A. Müller, J. Ranke, B. Ondruschka and B. Jastorff, Green Chem., 2008, 10, 1152; (e) H. Zhao, H. M. Brown, J. E. Holladay and Z. C. Zhang, Top. Catal., 2012, 55, 33-37.

21 E. Ennis and S. T. Handy, Curr. Org. Synth., 2007, 4, 381-389.

22 NMR studies indicate that the main side product at elevated temperatures is 2-(acetylsulfanyl)ethyl acetate, the adduct of thiirane and acetic anhydride, which is suported by our suggested mechanism (Scheme 2). This side product is easily and completely removed during the standard workup procedure, but to obtain maximum yields, reactions at room temperature are preferred.

23 C. V. Stevani, D. F. Lima, V. G. Toscano and W. J. Baader, J. Chem. Soc., Perkin Trans. 2, 1996, 989-995.

24 For ionic liquid crystals, for instance read: (a) K. V. Axenov and S. Laschat, Materials, 2011, 4, 206-259; (b) K. Binnemans, Chem. Rev., 2005, 105, 4148-4204; (c) P. H. J. Kouwer and T. M. Swager, J. Am. Chem. Soc., 2007, 129, 14042-14052.

25 From literature it is known that carboxylate anions form strong hydrogen bonds (reference a) and tend to form dimers linked by an hydrogen atom (reference b): $(a)$ P. Schah-Mohammedi, I. G. Shenderovich, C. Detering, H.-H. Limbach, P. M. Tolstoy, S. N. Smirnov, G. S. Denisov and N. S. Golubev, J. Am. Chem. Soc., 2000, 122, 1287812879; (b) P. M. Tolstoy, P. Schah-Mohammedi, S. N. Smirnov, N. S. Golubev, G. S. Denisov and H.-H. Limbach, J. Am. Chem. Soc., 2004, 126, 5621-5634.

26 K. M. Johansson, E. I. Izgorodina, M. Forsyth, D. R. MacFarlane and K. R. Seddon, Phys. Chem. Chem. Phys., 2008, 10, 2972-2978.

27 K. Nakashima, T. Maruyama, N. Kamiya and M. Goto, Anal. Biochem., 2008, 374, 285-290.

28 (a) A. Wang, J. Hendel and F.-I. Auzanneau, Beilstein J. Org. Chem., 2010, 6, 17; (b) T. G. Back, D. L. Baron and K. Yang, J. Org. Chem., 1993, 58, 2407-2413; (c) N. Barbero and R. Martin, Org. Lett., 2012, 14, 796-799; (d) C. KuehmCaubère, A. Guilmart, S. Adach-Becker, Y. Fort and P. Caubère, Tetrahedron Lett., 1998, 39, 8987-8990.

29 (a) B.-Y. Hao, J.-Q. Liu, W.-H. Zhang and X.-Z. Chen, Synthesis, 2011, 1208-1212; (b) A. J. Pearson, A. Alimardanov, A. A. Pinkerton and D. A. Parrish, J. Org. Chem., 1998, 63, 6610-6618; (c) M. J. Melnick and S. M. Weinreb, J. Org. Chem., 1988, 53, 850-854.

30 W. J. M. Pieters, J. Freel and R. B. Anderson, US Pat., 3,796,670, 1970.

31 Preliminary ${ }^{27} \mathrm{Al} \mathrm{NMR}$ studies indicate that the acetate anion is replaced by aluminate anions.

32 (a) K. S. Kim, D. Demberelnyamba and H. Lee, Langmuir, 2004, 20, 556-560; (b) K. S. Kim, N. D. Demberelnyamba, S. W. Yeon, S. Choi, J. H. Cha and H. Lee, Korean J. Chem. Eng., 2005, 22, 717-720; (c) R. Tatumi and H. Fujihara, Chem. Commun., 2005, 83-85.

33 To preserve the carboxylate anion, the use of phosphines is preferred over the commonly used DTT that requires basic conditions for its application.

34 C. Baleizao, B. Gigante, H. Garcia and A. Corma, Tetrahedron Lett., 2003, 44, 6813-6816.

35 (a) A. Alvarez Fernandez, L. T. de Haan and P. H. J. Kouwer, J. Mater. Sci. Eng. A, 2013, 1, 354; (b) J. G. Huddleston, A. E. Visser, W. M. Reichert, H. D. Willauer, G. A. Broker and R. D. Rogers, Green Chem., 2001, 3, 156-164. 